\title{
Giant cell tumour of the femur in a 9-year-old girl, resulting in severe leg length discrepancy
}

\author{
Masatoshi Oba, ${ }^{1,2}$ Yutaka Inaba, ${ }^{1}$ Jiro Machida, ${ }^{2}$ Tomoyuki Saito ${ }^{1}$
}

${ }^{1}$ Department of Orthopedics, Yokohama City University, Yokohama, Japan ${ }^{2}$ Department of Pediatric Orthopedics, Kanagawa Children's Medical Center, Yokohama, Kanagawa, Japan

\section{Correspondence to} Dr Masatoshi Oba, t126014a@yokohama-cu.ac.jp

Accepted 28 February 2016
CrossMark

To cite: Oba M, Inaba $Y$, Machida J, et al. BMJ Case Rep Published online: [please include Day Month Year] doi:10.1136/bcr-2015214265

\section{SUMMARY}

Giant cell tumour of bone (GCTB) is a rare benign tumour noted before physeal closure. GCTB cases in patients younger than 10 years are especially uncommon. The authors report the case of a 9-year-old girl with a GCTB of the distal femur. After initial intralesional excision and curettage of the tumour, local recurrence occurred, which needed two more additional surgeries to treat. The primary tumour and the local relapse invaded the growth plate of the right distal femur, leading to growth disturbance of the femur and requiring leg lengthening using llizarov apparatus. Surgeons should note the possibility of this rare condition while treating radiographic lytic lesions even in skeletally immature patients. The occurrence of late limb length discrepancy would be more likely in younger patients.

\section{BACKGROUND}

Giant cell tumour of bone (GCTB), which occurs mainly in patients aged $20-40$ years, is one of the differential diagnoses of radiographic lytic bone lesions in the metaphyseal-epiphyseal area of long bones. ${ }^{1}$ In skeletally immature patients, the primary diagnosis for radiographic lytic lesions is chondroblastoma. ${ }^{2}$ We present a rare case of a 9-year-old girl with GCT in her right distal femur, which required repetitive surgery and resulted in leg length discrepancy. The occurrence of GCTB in a patient younger than 10 years is very rare considering that most reported GCTB cases in skeletally immature patients have been of those in their late teens. ${ }^{3}{ }^{4}$ Serious growth disturbance that required leg lengthening was a unique sequela of the presented case.

\section{CASE PRESENTATION}

An otherwise healthy 9-year-old girl presented with right knee pain on exercise. She had no specific trauma or medical history. Since 2 months before her first visit, her right knee had started to hurt while running. She felt discomfort around her right knee on walking, which became painful during exercise. On physical examination, her right knee was slightly swollen with no localised heat and no signs of joint effusion. She and her parents denied any patient history of swelling, redness or localised heat in other joints. There were no other specific abnormal findings on either of her lower limbs on standard physical examinations.

\section{INVESTIGATIONS}

Standard radiograph of the right knee showed a geographic lytic lesion with marginal sclerosis in the epiphysis of the distal femur (figure 1). The lesion extended proximally beyond the growth plate. The lytic lesion was also seen on a CT scan as a very low-density area, and the subchondral bone of the weight-bearing area of the distal femur was thinned by invasion of the lytic lesion (figure 2). There was neither internal calcification nor any periosteal reaction associated with the lytic lesion. MRI showed heterogeneous low-to-intermediate intensity on T1-weighted imaging (figure 3) and high intensity on T2-weighted imaging. Cortical destruction of the dorsal aspect of the distal femur and soft tissue involvement were confirmed on coronal and sagittal slices of the MRI.

\section{TREATMENT}

Intralesional curettage was performed as the first surgery using the standard posterior approach to the knee joint. On exposure of the posterior aspect of the distal femur, a yellowish-grey tumour perforating the intercondylar cortex was seen. After radical intralesional curettage of the tumour, the cancellous bone harvested from the ilium was grafted to reinforce the weight-bearing portion of the femoral condyles. The tumour specimen was analysed pathologically. Microscopically, the tumour specimen showed dense proliferation of

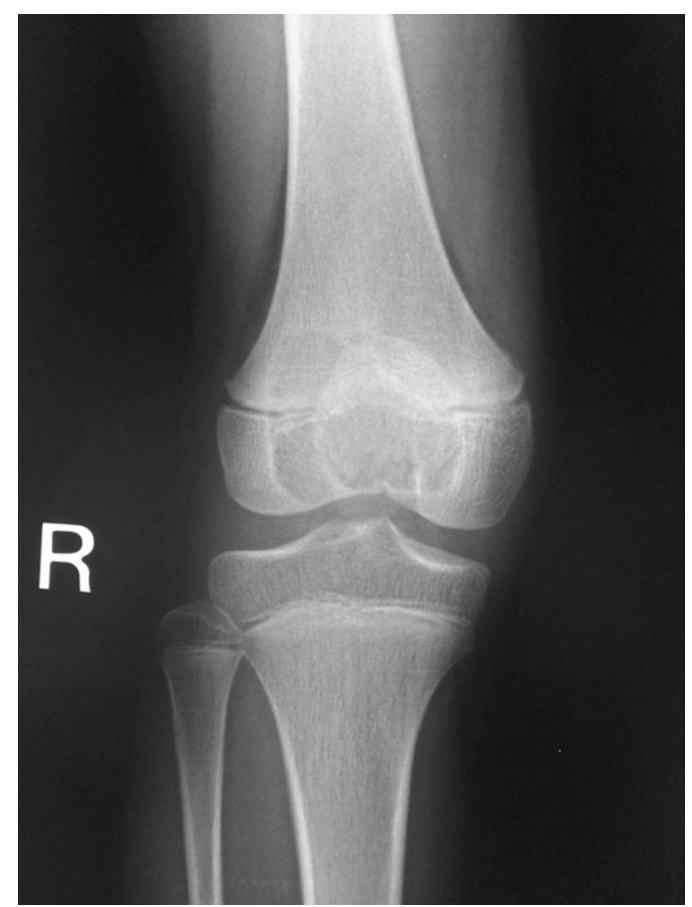

Figure 1 Plain anteroposterior radiograph of the right knee at the first visit. 


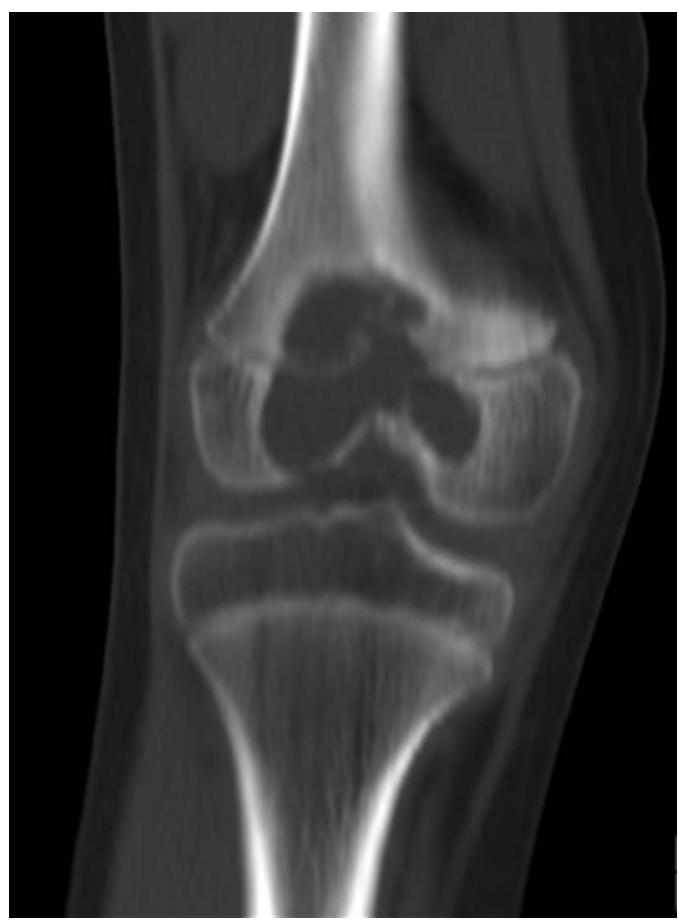

Figure 2 Preoperative coronal CT reconstruction image of the right knee.

spindle-shaped or polygonal mononuclear cells, with scattered multinucleated giant cells (figures 4 and 5). No chondroid matrix was seen on any slides, and immunohistochemistry of the tumour specimen was negative for S-100 protein (figure 6). ${ }^{15}$ These pathological features were consistent with

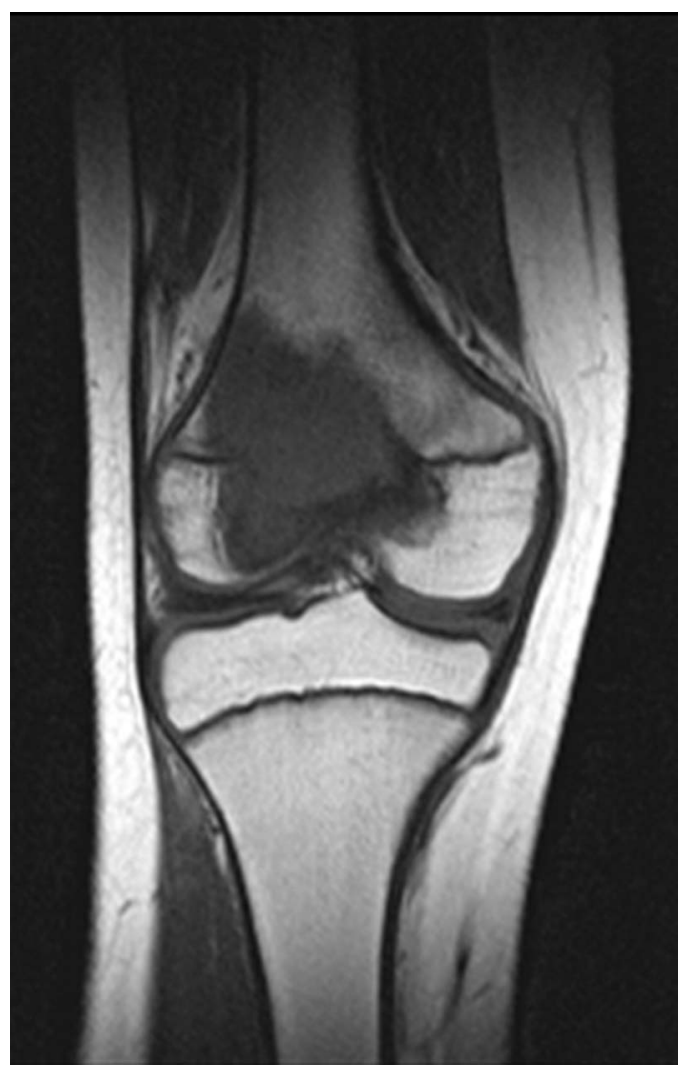

Figure 3 Preoperative T1-weighted MRI.

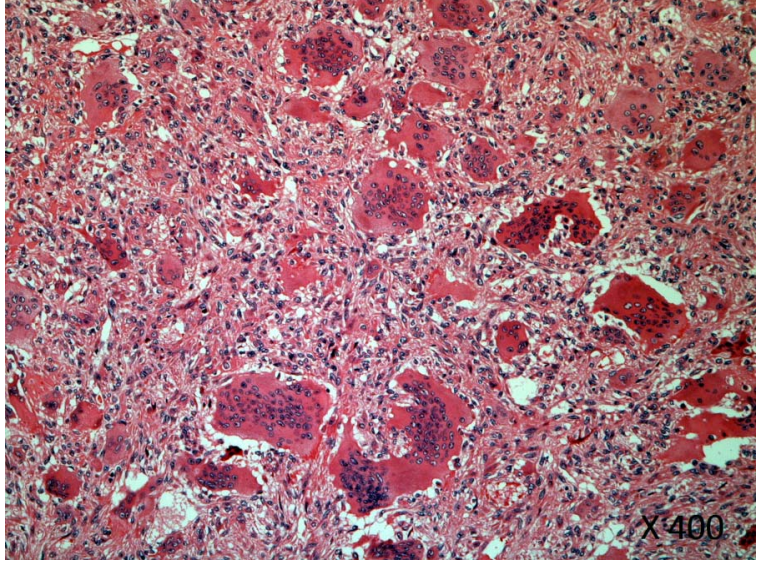

Figure $4 \quad H \& E$ section of the tumour resected at the first surgery.

GCTB, and recurrence of the tumour was strongly anticipated. No chromosomal analysis of the tumour specimen was performed in this case. Three months after the first surgery, local recurrence of the tumour was confirmed by MRI. We performed a second intralesional curettage of the relapsed tumour combined with Argon plasma coagulation for the bone cavity wall after the tumour resection. The pathological findings of the resected specimen from the second surgery were also consistent with GCTB. Two years after the second surgery, another local recurrence was confirmed by enhanced MRI. Thorough curettage of the tumour was performed again for a third time, and the inner wall of the residual bone cavity of the right distal femur was coagulated with spray mode electrocautery.

\section{OUTCOME AND FOLLOW-UP}

There was neither local recurrence nor distant metastasis of the GCTB for over 8 years after the third surgery. However, the growth plate of the right distal femur had been largely invaded by both, the primary and recurrent tumours. We retrospectively analysed the extent of intact growth plate using MRI taken at the second recurrence of the GCTB. T1-weighted coronal images of the affected knee were imported to the image analyser (3D Slicer 4.4$)^{6}$ to map the intact growth plate. It revealed that less than $40 \%$ of the intact growth plate of the distal femur had remained, which strongly suggested late growth disturbance. ${ }^{7}$ When the patient reached skeletal maturity at 15 years, the leg length discrepancy became more than $3 \mathrm{~cm}$ (figure 7). We used

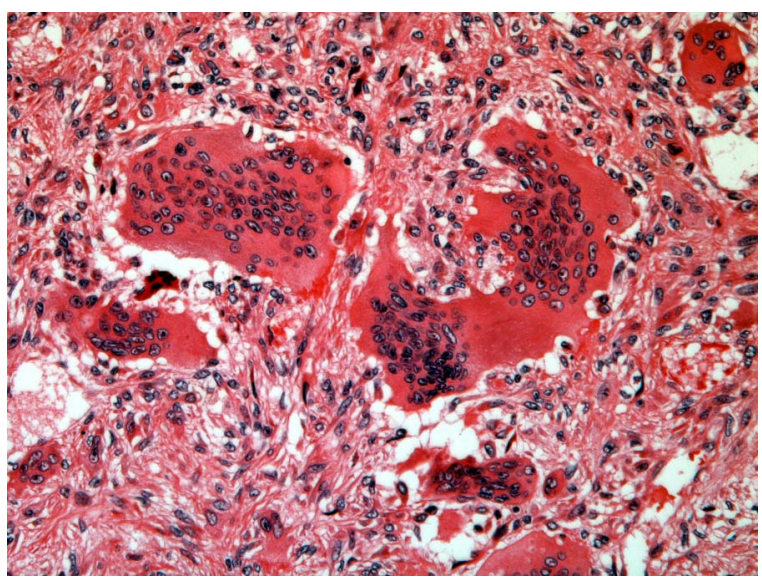

Figure 5 Enlarged image of a part of figure 4 showing polynuclear giant cell surrounded by mononuclear stromal cells. 


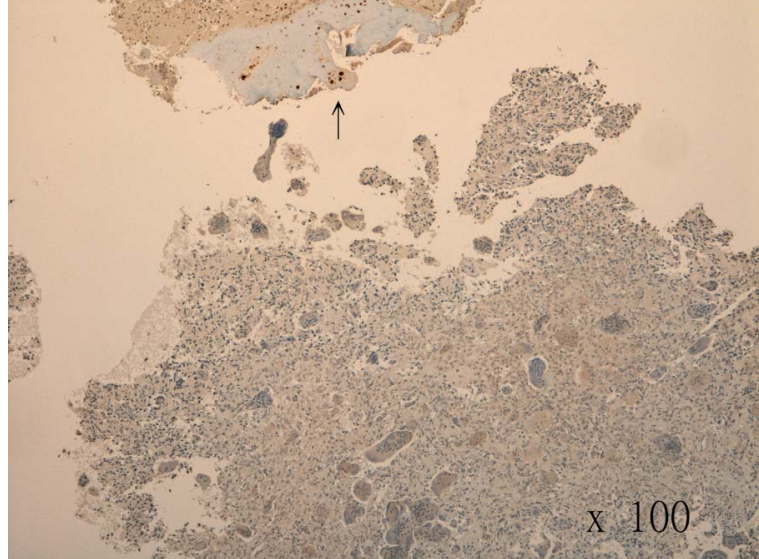

Figure 6 S-100 immunostain of the tumour specimen showing that the giant and stromal cells were negative. Chondrocytes in the articular cartilage (black arrow) served as a positive control.

the Ilizarov technique to correct her leg length discrepancy, for which $4 \mathrm{~cm}$ lengthening was required. More than 5 years have passed since the end of the leg lengthening process. The patient

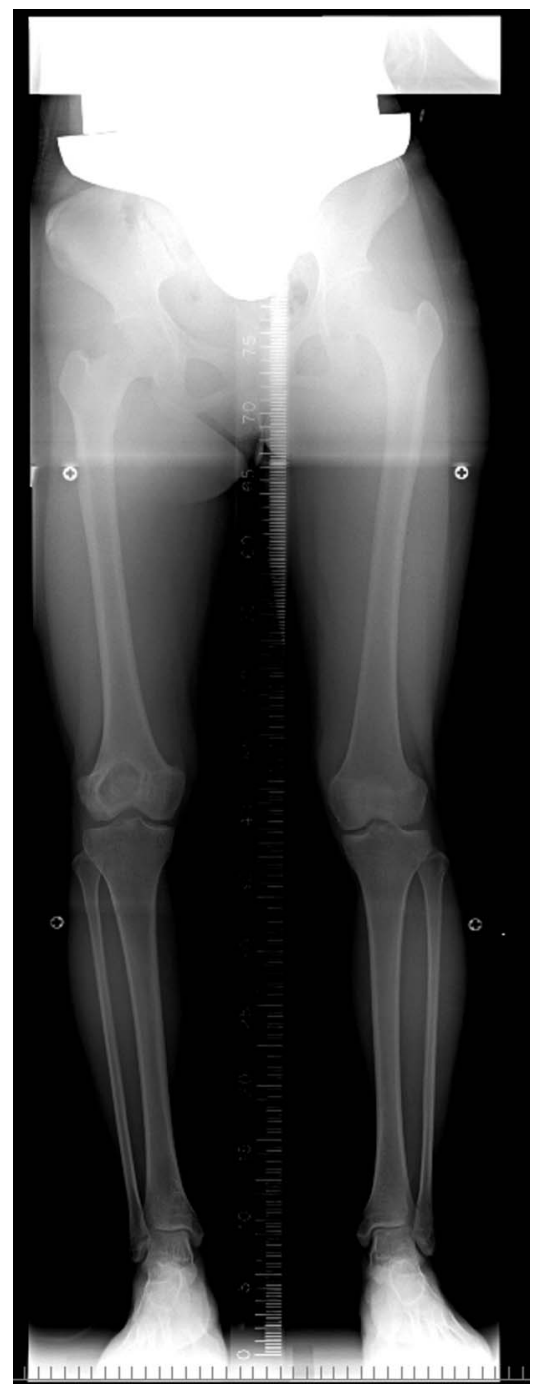

Figure 7 Standing long leg alignment view at 4 years after the third surgery.

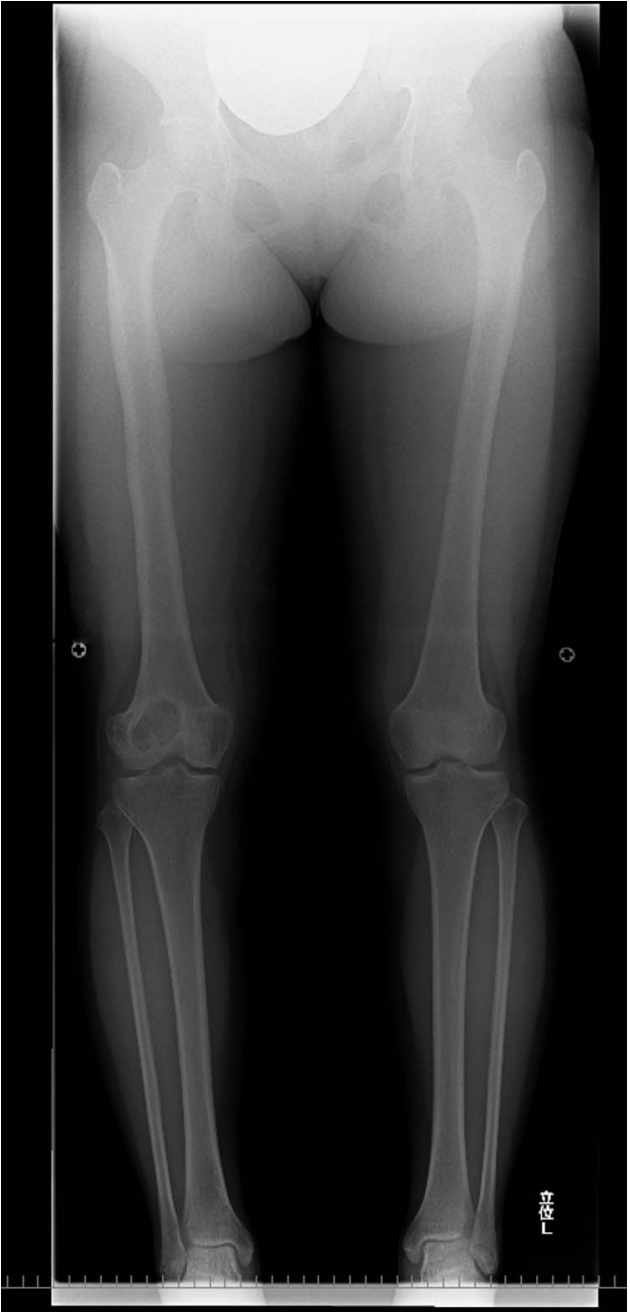

Figure 8 Standing long leg alignment view at the patient's last visit.

reported feeling neither difficulty nor discomfort in daily life at her last visit (figure 8).

\section{DISCUSSION}

Clinical or radiographic diagnosis of the GCTB in skeletally immature patients is difficult. Typically, GCTB appears as a lytic lesion with well-defined and non-sclerotic margins on conventional radiographs. However, most lytic lesions in the epiphyseal or metaphyseal regions of long bones with open physes are found to be chondroblastomas, and the possibility of other malignant tumours (ie, osteosarcoma) should be considered. Internal calcification of lytic lesions is the characteristic sign of chondroblastomas, but this sign is not seen in almost half the cases. $^{8}{ }^{9}$ CT and MRI findings are usually not specific. ${ }^{10}$ Definitive diagnosis therefore requires open biopsy or core needle biopsy. ${ }^{11}$

The main concern in the treatment of GCTB is its high potential for recurrence. Radical treatment for GCTB usually requires iterative curettage or en bloc resection combined with various adjuvant therapies (eg, cryosurgery, electrocautery, cementation, or Argon laser coagulation). ${ }^{1}$ The case series study from Puri et $a l^{12}$ on GCTB in skeletally immature patients reported that the tumours in all recurrent cases were classified as grade 3 of Enneking's system, ${ }^{13}$ which signifies soft tissue involvement of the tumour. The GCT of the femur in the present case was also a grade 3 tumour with extra-osseous 
invasion, for which two further radical surgeries after the first intralesional curettage were required. We did not perform a cytogenetic analysis of the tumour specimen. However, the presence of chromosomal aberration of the tumour could suggest the tendency of recurrence of the tumour. ${ }^{14}$

Along with the problem of local recurrence, premature physeal closure is also a concern in skeletally immature patients, since extension of the GCT itself and local recurrence of the tumour requiring repetitive surgery may damage the adjacent growth plate. ${ }^{15}$ However, similar case reports have not often described the occurrence of leg length discrepancy or angular deformity after the treatment for GCT. Harsha et al ${ }^{16}$ presented the case of a 13-year-old girl with GCTB in the distal femoral epiphysis. Despite radical treatment consisting of intralesional curettage and cryosurgery of the lesion, which included more than one-third of the distal femoral growth plate, the authors reported that neither angular deformity nor leg length discrepancy had occurred on reaching skeletal maturity. Puri et al ${ }^{12}$ also reported that angulation and/or shortening of the lower extremity requiring further corrective surgery had not occurred in their cases at average age of 15.8 years (range 13-17). The possible explanation for this small incidence of problematic deformity would be that the majority of those reported cases had already come close to skeletal maturity. Our patient was 9 years old at presentation, with a relatively longer bone growth period remaining; therefore, the late limb deformity owing to the damaged physis would be more likely to occur. ${ }^{15}$

Although GCTB in skeletally immature patients is rare, surgeons should note that it is difficult to distinguish GCTB from chondroblastoma with routine diagnostic imaging, and often we

Learning points

- Giant cell tumour of bone (GCTB) in skeletally immature patients is rare but can occur even in patients younger than 10 years.

- Repeated operations combined with adjuvant therapy will usually be required to prevent local recurrence with a pathologically confirmed diagnosis of GCTB.

- Growth disturbance of the affected limb at skeletal maturity is more likely to occur in younger patients. only discover the definitive diagnosis from the pathological investigation of the resected specimen after the surgery. Growth plate damage due to the tumour invasion can lead to limb deformity, especially if the patient has a substantial time remaining until reaching skeletal maturity.

Acknowledgements The authors are grateful to Dr Yukichi Tanaka (Department of Pathology, Kanagawa Children's Medical Center) for helpful discussions and pathological supervision.

Contributors $\mathrm{MO}$ and JM participated in the care and surgery of the patient. MO, $\mathrm{JM}$ and $\mathrm{YI}$ wrote the initial manuscript. The final manuscript was written by $\mathrm{MO}$ and $\mathrm{YI}$ under supervision of TS.

Competing interests None declared.

\section{Patient consent Obtained.}

Provenance and peer review Not commissioned; externally peer reviewed.

\section{REFERENCES}

1 Raskin KA, Schwab JH, Mankin HJ, et al. Giant cell tumor of bone. J Am Acad Orthop Surg 2013;21:118-26.

2 Sailhan F, Chotel F, Parot R. Chondroblastoma of bone in a pediatric population. J Bone Joint Surg Am 2009;91:2159-68.

3 Picci $\mathrm{P}$, Manfrini $\mathrm{M}$, Zucchi $\mathrm{V}$, et al. Giant-cell tumor of bone in skeletally immature patients. J Bone Joint Surg Am 1983;65:486-90.

4 Schütte HE, Taconis WK. Giant cell tumor in children and adolescents. Skeletal Radiol 1993;22:173-6.

5 Monda L, Wick MR. S-100 protein immunostaining in the differential diagnosis of chondroblastoma. Hum Pathol 1985;16:287-93.

6 Fedorov A, Beichel R, Kalpathy-Cramer J, et al. 3D Slicer as an image computing platform for the Quantitative Imaging Network. Magn Reson Imaging 2012;30:1323-41.

7 Shailam R, Jaramillo D, Kan JH. Growth arrest and leg-length discrepancy. Pediatr Radiol 2013:43:155-65.

8 Kricun ME, Kricun R, Haskin ME. Chondroblastoma of the calcaneus: radiographic features with emphasis on location. AJR Am J Roentgenol 1977;128:613-16.

9 Erickson JK, Rosenthal DI, Zaleske DJ, et al. Primary treatment of chondroblastoma with percutaneous radio-frequency heat ablation: report of three cases. Radiology 2001;221:463-8.

10 Chakarun CJ, Forrester DM, Gottsegen CJ, et al. Giant cell tumor of bone: review, mimics, and new developments in treatment. Radiographics 2013;33:197-211.

11 van der Heijden L, Dijkstra PDS, van de Sande MAJ, et al. The clinical approach toward giant cell tumor of bone. Oncologist 2014;19:550-61.

12 Puri A, Agarwal MG, Shah M, et al. Giant cell tumor of bone in children and adolescents. J Pediatr Orthop 2007;27:635-9.

13 Enneking WF, Spanier SS, Goodman MA. A system for the surgical staging of musculoskeletal sarcoma. Clin Orthop Relat Res 1980;153:106-20.

14 Bridge JA, Neff JR, Bhatia PS, et al. Cytogenetic findings and biologic behavior of giant cell tumors of bone. Cancer 1990;65:2697-703.

15 Schuppers HA, van der Eijken JW. Chondroblastoma during the growing age. J Pediatr Orthop B 1998;7:293-7.

16 Harsha A, Villalobos CE, Rybak LD, et al. Orthopaedic. radiology. pathology conference: painful distal femur lesion in a 13-year-old girl. Clin Orthop Relat Res 2009;467:2200-5.

Copyright 2016 BMJ Publishing Group. All rights reserved. For permission to reuse any of this content visit

http://group.bmj.com/group/rights-licensing/permissions.

BMJ Case Report Fellows may re-use this article for personal use and teaching without any further permission.

Become a Fellow of BMJ Case Reports today and you can:

- Submit as many cases as you like

- Enjoy fast sympathetic peer review and rapid publication of accepted articles

- Access all the published articles

- Re-use any of the published material for personal use and teaching without further permission

For information on Institutional Fellowships contact consortiasales@bmjgroup.com

Visit casereports.bmj.com for more articles like this and to become a Fellow 